\title{
ACTIVATION ANALYSIS OF HISTORICAL SAMPLES AND NEUTRON SPECTRUM DETERMINATION AT VR-1 TRAINING REACTOR
}

\author{
Jan ŠTuRma*, Milan ŠTeFÁniK \\ Department of Nuclear Reactors, Faculty of Nuclear Sciences and Physical Engineering, Czech Technical \\ University in Prague, Břehová 7, 11519 Praha, Czech Republic \\ * corresponding author: sturmja2@fjfi.cvut.cz
}

\begin{abstract}
Vertical irradiation channel of the VR-1 training reactor of the Department of Nuclear Reactors CTU was used for activation analysis of historical samples from the 14th to the 19th century. For determination of mass fractions of materials such as copper, gold and silver in irradiated samples, the relative method of activation analysis was used. Further, a set of 24 activation detectors of 12 various materials served for the determination of neutron spectrum of the VR-1 reactor using analytical method; moreover the analytical solution was compared to unfolded spectrum obtained from SAND-II deconvolution program.
\end{abstract}

KEYWORDS: activation analysis, reaction rate, neutron spectroscopy, historical samples, Westcott formalism.

\section{INTRODUCTION}

Research reactors can be used as a significant source of radiation, especially neutrons. There are several ways of neutron applications from medical purposes such as the boron capture therapy to material testing, or transmutation technologies et cetera. One possible application is also a radioanalytical method called the neutron activation analysis. This method is based on intentional production of radionuclides in studied materials through the neutron interactions; it is an exact tool that can be used to qualitatively and quantitatively determine composition of various samples. The pool-type light water training reactor VR-1 of the Department of Nuclear Reactors CTU is frequently used for purposes of neutron activation analysis especially due to its experimental equipment such as vertical and horizontal irradiation channels. Presented project aims to determine the composition of historical samples and neutron spectrum of VR-1 training reactor by using the neutron activation technique.

\subsection{Neutron aCtivaton AnAlysis}

Measuring the characteristic radiation of the sample, usually gamma or beta particles, produced in radionuclide decays, the saturated activity of irradiated sample can be determined as

$$
A_{\mathrm{SAT}}=\frac{\lambda t_{\mathrm{real}} \frac{S\left(E_{\gamma}\right)}{t_{\text {live } \varepsilon_{\mathrm{FEP}}\left(E_{\gamma}\right) I_{\gamma}\left(E_{\gamma}\right)}}}{\left(1-\mathrm{e}^{\left(-\lambda t_{a}\right)}\right) \mathrm{e}^{\left(-\lambda t_{c}\right)}\left(1-\mathrm{e}^{\left(-\lambda t_{\mathrm{real}}\right)}\right)} \prod_{i} C_{i}
$$

where $\lambda$ is the decay constant of measured radionuclide, $t_{\text {real }}$ is the real time of the gamma spectrum measurement, $t_{\text {live }}$ is the live time of the measurement, $S\left(E_{\gamma}\right)$ is number of counts in the full energy peak at energy $E_{\gamma}, \varepsilon_{\mathrm{FEP}}$ is the detector efficiency for full en- ergy peak, $I_{\gamma}$ is the probability of gamma emission, $t_{a}$ is the irradiation time and $t_{c}$ is the cooling time. Possible corrections, e.g. the correction for reactor power fluctuation, self-shielding of gamma radiation or the correction for gamma coincidences, are represented by factors $C_{i}$.

For determination of sample composition, the relative method of the activation analysis is standardly used. Studied samples are irradiated together with the activation standards of known composition. The amount of investigated material in the sample can be determined as follows

$$
\frac{A_{\mathrm{St}}}{m_{\mathrm{St}}}=\frac{A_{\mathrm{Sp}}}{m_{\mathrm{Sp}}}
$$

where $A_{\mathrm{St}}$ and $A_{\mathrm{Sp}}$ are the saturated activities of produced radionuclide in standard or in sample, and $m_{\mathrm{St}}$ and $m_{\mathrm{Sp}}$ are the masses of investigated material in standard foil or in sample.

Other technique of neutron activation analysis is the absolute method, where the amount of material in sample is defined as

$$
m_{\mathrm{Sp}}=\frac{A_{\mathrm{Sp}} M}{N_{\mathrm{A}} \phi \overline{\sigma_{\mathrm{a}}}}
$$

where $M$ is the molar mass of examined material, $N_{\mathrm{A}}$ is the Avogadro's number, $\phi$ is the integral neutron flux and $\overline{\sigma_{\mathrm{a}}}$ is the spectrum averaged microscopic activation cross-section.

\subsection{Neutron SPECTRUM Determination By ACTIVATION DETECTORS}

Methods of neutron activation analysis can be also used for measurement of neutron flux using activation detectors of various materials. The response of the 
detector to the neutron field per one nuclei, called reaction rate, can be calculated as

$$
R_{\mathrm{R}}=\frac{A_{\mathrm{SAT}}}{N_{0}}
$$

where $N_{0}$ is the number of target nuclei in the activation detector.

Reaction rates obtained by irradiating the set of various detectors together with the cadmium cover as well as some threshold interactions make possible to reconstruct the neutron field using analytical methods. The analytical expression of neutron flux is

$$
\phi\left(E_{\mathrm{n}}\right)=\phi_{\mathrm{t}}\left(E_{\mathrm{n}}\right)+\phi_{\mathrm{e}}\left(E_{\mathrm{n}}\right) \Delta_{1} \Delta_{2}+\phi_{\mathrm{f}}\left(E_{\mathrm{n}}\right) .
$$

Neutron flux in thermal energy region, $\phi_{\mathrm{t}}\left(E_{\mathrm{n}}\right)$, is for well moderated reactors defined according to the Westcott formalism as [1]

$$
\phi_{\mathrm{t}}\left(E_{\mathrm{n}}\right)=\frac{E_{\mathrm{n}}}{\left(k T_{\mathrm{n}}\right)^{2}} \mathrm{e}^{-\frac{E_{\mathrm{n}}}{k T_{\mathrm{n}}}} \frac{R_{\mathrm{R}}^{\mathrm{t}}}{g\left(T_{\mathrm{n}}\right) \sigma_{0}},
$$

where $E_{\mathrm{n}}$ is the energy of neutrons, $k$ is the Boltzmann constant, $T_{\mathrm{n}}$ is the thermodynamic temperature of neutrons, $R_{\mathrm{R}}^{\mathrm{t}}$ is the response of detector to thermal neutrons, $g\left(T_{\mathrm{n}}\right)$ is the deviation of the activation cross section from the law $1 / v$ in thermal energy region and $\sigma_{0}$ is the activation cross-section for energy $E_{\mathrm{n}}=0.0253 \mathrm{eV}$.

The activation detector in cadmium cover is activated mostly by neutrons of energies associated with the energy of most significant resonance in crosssection, and therefore it is suitable to determine the epithermal neutron flux. Discrete values of neutron flux for resonance energies Eres of activation materials are defined as 2

$$
\phi_{\mathrm{t}}\left(E_{\mathrm{res}}\right)=\frac{R_{\mathrm{R}}^{\mathrm{epi}} K}{\int_{E_{1}}^{E_{2}} \sigma\left(E_{\mathrm{n}}\right) \mathrm{d} E_{\mathrm{n}}},
$$

where $R_{\mathrm{R}}^{\text {epi }}$ is the response of the detector in cadmium cover to the neutron field, $K$ is the proportional representation of the most significant resonance in the cross-section in epithermal energy region, and $E_{1}$ or $E_{2}$ represents the lower or upper boundary of resonance. Experimentally obtained discrete values of neutron flux can be fitted using the expected shape of epithermal reactor spectrum in the form of $a / E_{\mathrm{n}}^{x}$, and consequently it can be smoothly connected to the thermal and fast analytical solution of neutron spectra using the joining functions $\Delta_{1}$ and $\Delta_{2}$ defined as

$$
\Delta_{1}=\frac{1}{1+\left(\frac{4.95 k T_{\mathrm{n}}}{E_{\mathrm{n}}}\right)^{7}}, \quad \Delta_{2}=\exp \left(-\frac{E_{\mathrm{n}}}{3 \cdot 10^{5}}\right) .
$$

Threshold activation detectors are serving to express the reaction rates $R_{\mathrm{R}}^{\mathrm{f}}$ of activation detectors to the fast neutron region. In fast region, the differential neutron flux is described as

$$
\phi_{\mathrm{f}}\left(E_{\mathrm{n}}\right)=\frac{R_{\mathrm{R}}^{\mathrm{f}}}{\overline{\sigma_{\mathrm{t}}}} S\left(E_{\mathrm{n}}\right),
$$

where $\overline{\sigma_{\mathrm{t}}}$ is the spectrum averaged threshold crosssection and the $S\left(E_{\mathrm{n}}\right)$ is the fission neutron spectrum.

\section{Materials and Methods}

\subsection{ACtivation EXPERIMENTS OF HISTORICAL SAMPLES}

The vertical irradiation channel of VR-1 training reactor was used to perform the activation experiments of historical coins; the main purpose was to determine the qualitative and quantitative composition by employing the relative method of neutron activation analysis.

In 2014, six historical coins were irradiated together with the reference standards of expected materials. In particular, Kurush-1923, Pfennig-1745, Kreutzer-1843, Parvus-14.century, Centessimo-1852, and Heller-1854 were studied, and copper, gold, silver, and nickel foils were used as activation standards in two sets. In 2015, another three coins (Korona-1893, Kreutzer-1861, and Pfennig-1776) together with the silver and copper standards in the form of foils were irradiated.

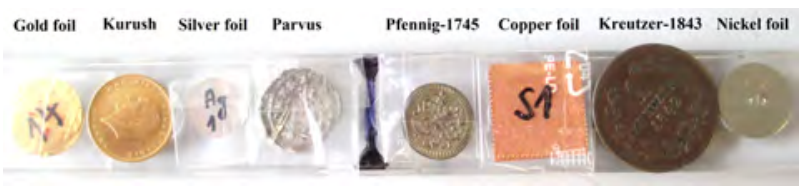

FiguRE 1. First set of historical samples with reference materials.

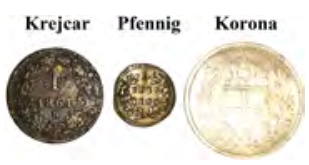

FiguRE 2. Third set of historical coins analyzed using activation analysis.

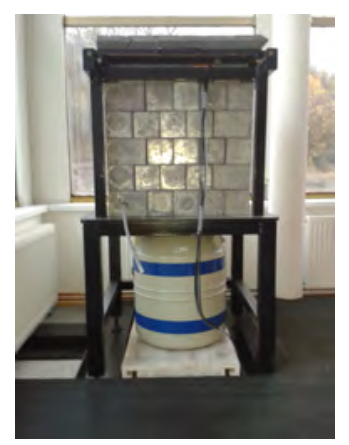

Figure 3. HPGe detector in Pb shielding.

Each set of samples was irradiated twice. The first irradiation at low reactor power was performed to disprove the presence of inappropriate isotopes, such as ${ }^{59}$ Co. Because after irradiation of such isotope, the long term radionuclide is produced, and it is inconvenient. Gamma lines of ${ }^{116 \mathrm{~m}}$ In were observed in the spectrum of one sample, and due to this fact, the 
indium reference activation standard was added to the set before main irradiation at the nominal power. During the second irradiation, the reactor was operated at power-level of $1 \mathrm{~kW}$, and the irradiating time was set to $15-30 \mathrm{~min}$.

After the main irradiation, the gamma-ray spectra of irradiated samples were measured by the semiconductor HPGe detector. For all radionuclides observed in spectra, the saturated activity was determined by using the equation (1).

\subsection{IRRADIATIONG OF ACTIVACTION DETECTORS}

Altogether 24 activation detectors made of 12 various materials (Al, Ag, Au, Cu, Fe, In, LuAl, Mn, Mo, $\mathrm{NaCl}, \mathrm{U}$ and $\mathrm{W}$ ) in the form of thin foils ( $\mathrm{NaCl}$ detector had a form of tablet) were irradiated in the vertical irradiation channel at mid-height of reactor core of VR-1 reactor. Irradiating time was $15-45 \mathrm{~min}$ at the reactor-power of $1 \mathrm{~kW}$. Activation materials were chosen with respect to the activation cross-sections in order to cover all energy regions of reactor spectrum; therefore the cadmium cover and some threshold detectors were used. After irradiation, the gamma spectra of detectors were measured. For each observed reaction, the reaction rates were determined using the expression (3).

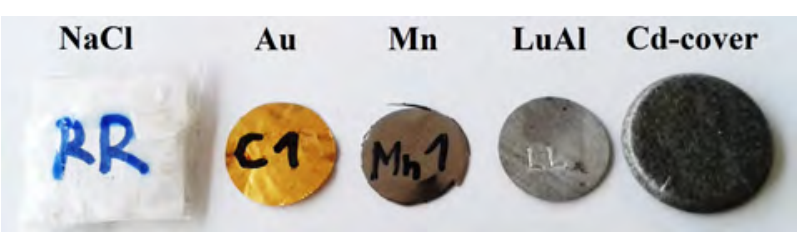

FIGURE 4. Set of activation detectors.

\begin{tabular}{|c|c|c|c|}
\hline Reaction & $T_{1 / 2}$ & $R_{R}\left[\mathrm{~s}^{-1}\right]$ & $\operatorname{Dev}\left[\mathrm{s}^{-1}\right]$ \\
\hline${ }^{197} \mathrm{Au}(\mathrm{n}, \gamma){ }^{198} \mathrm{Au}$ & 2.70 days & $1.77 \cdot 10^{-13}$ & $4.04 \cdot 10^{-15}$ \\
\hline${ }^{197} \mathrm{Au}(\mathrm{n}, \gamma){ }^{198} \mathrm{Au}-\mathrm{Cd}$ & 2.70 days & $3.70 \cdot 10^{-14}$ & $2.61 \cdot 10^{-16}$ \\
\hline${ }^{63} \mathrm{Cu}(\mathrm{n}, \gamma){ }^{64} \mathrm{Cu}$ & 12.70 hours & $7.89 \cdot 10^{-15}$ & $1.62 \cdot 10^{-16}$ \\
\hline${ }^{63} \mathrm{Cu}(\mathrm{n}, \gamma){ }^{64} \mathrm{Cu}-\mathrm{Cd}$ & 12.70 hours & $3.51 \cdot 10^{-16}$ & $5.50 \cdot 10^{-18}$ \\
\hline${ }^{186} \mathrm{~W}(\mathrm{n}, \gamma){ }^{187} \mathrm{~W}$ & 23.72 hours & $9.05 \cdot 10^{-14}$ & $7.77 \cdot 10^{-16}$ \\
\hline${ }^{186} \mathrm{~W}(\mathrm{n}, \gamma){ }^{187} \mathrm{~W}-\mathrm{Cd}$ & 23.72 hours & $1.56 \cdot 10^{-14}$ & $1.20 \cdot 10^{-16}$ \\
\hline${ }^{98} \mathrm{Mo}(\mathrm{n}, \gamma){ }^{99} \mathrm{Mo}$ & 65.94 hours & $8.46 \cdot 10^{-16}$ & $2.12 \cdot 10^{-17}$ \\
\hline${ }^{98} \mathrm{Mo}(\mathrm{n}, \gamma){ }^{99} \mathrm{Mo}-\mathrm{Cd}$ & 65.94 hours & $5.61 \cdot 10^{-16}$ & $1.46 \cdot 10^{-17}$ \\
\hline${ }^{115} \operatorname{In}(\mathrm{n}, \gamma)^{116 \mathrm{~m}} \operatorname{In}-\mathrm{Cd}$ & $54.29 \mathrm{~min}$ & $4.06 \cdot 10^{-14}$ & $2.13 \cdot 10^{-16}$ \\
\hline${ }^{115} \operatorname{In}\left(\mathrm{n}, \mathrm{n}^{\prime}\right)^{115 \mathrm{~m}} \mathrm{In}$ & 4.47 hours & $1.44 \cdot 10^{-16}$ & $3.76 \cdot 10^{-18}$ \\
\hline${ }^{115} \operatorname{In}(\mathrm{n}, \gamma)^{116 \mathrm{~m}} \operatorname{In}$ & $54.29 \mathrm{~min}$ & $2.19 \cdot 10^{-13}$ & $1.79 \cdot 10^{-15}$ \\
\hline${ }^{238} \mathrm{U}(\mathrm{n}, \gamma){ }^{239} \mathrm{U}$ & $23.45 \mathrm{~min}$ & $8.70 \cdot 10^{-15}$ & $3.23 \cdot 10^{-17}$ \\
\hline${ }^{238} \mathrm{U}(\mathrm{n}, \gamma){ }^{239} \mathrm{U}-\mathrm{Cd}$ & $23.45 \mathrm{~min}$ & $4.99 \cdot 10^{-15}$ & $1.45 \cdot 10^{-17}$ \\
\hline${ }^{23} \mathrm{Na}(\mathrm{n}, \gamma){ }^{24} \mathrm{Na}-\mathrm{Cd}$ & 14.96 hours & $2.64 \cdot 10^{-17}$ & $4.01 \cdot 10^{-19}$ \\
\hline${ }^{27} \mathrm{Al}(\mathrm{n}, \mathrm{p}){ }^{27} \mathrm{Mg}$ & $9.46 \mathrm{~min}$ & $7.77 \cdot 10^{-18}$ & $3.12 \cdot 10^{-19}$ \\
\hline${ }^{27} \mathrm{Al}(\mathrm{n}, \alpha){ }^{24} \mathrm{Na}$ & 14.96 hours & $5.29 \cdot 10^{-19}$ & $4.12 \cdot 10^{-20}$ \\
\hline${ }^{56} \mathrm{Fe}(\mathrm{n}, \mathrm{p}){ }^{56} \mathrm{Mn}$ & 2.58 hours & $1.10 \cdot 10^{-18}$ & $2.72 \cdot 10^{-20}$ \\
\hline${ }^{109} \mathrm{Ag}(\mathrm{n}, \gamma){ }^{110 \mathrm{~m}} \mathrm{Ag}-\mathrm{Cd}$ & 249.79 days & $1.79 \cdot 10^{-15}$ & $7.59 \cdot 10^{-18}$ \\
\hline${ }^{55} \mathrm{Mn}(\mathrm{n}, \gamma){ }^{56} \mathrm{Mn}-\mathrm{Cd}$ & 2.58 hours & $9.25 \cdot 10^{-16}$ & $6.14 \cdot 10^{-18}$ \\
\hline${ }^{55} \mathrm{Mn}(\mathrm{n}, \gamma){ }^{56} \mathrm{Mn}$ & 2.58 hours & $2.37 \cdot 10^{-14}$ & $5.28 \cdot 10^{-16}$ \\
\hline${ }^{176} \mathrm{Lu}(\mathrm{n}, \gamma){ }^{177} \mathrm{Lu}-\mathrm{Cd}$ & 6.73 days & $6.89 \cdot 10^{-14}$ & $1.85 \cdot 10^{-15}$ \\
\hline${ }^{176} \mathrm{Lu}(\mathrm{n}, \gamma){ }^{177} \mathrm{Lu}$ & 6.73 days & $5.70 \cdot 10^{-12}$ & $5.05 \cdot 10^{-14}$ \\
\hline${ }^{23} \mathrm{Na}(\mathrm{n}, \gamma){ }^{24} \mathrm{Na}$ & 14.96 hours & $7.65 \cdot 10^{-16}$ & $7.82 \cdot 10^{-18}$ \\
\hline${ }^{37} \mathrm{Cl}(\mathrm{n}, \gamma){ }^{38} \mathrm{Cl}$ & $37.24 \mathrm{~min}$ & $7.01 \cdot 10^{-16}$ & $9.07 \cdot 10^{-18}$ \\
\hline
\end{tabular}

TABLE 1. Reaction rates of irradiated activation detectors.

\section{Results}

\subsection{AnAlysis OF Historical COINS COMPOSITION}

The relative method of neutron activation analysis was used to determine the quantitative composition of five materials in all irradiated historical coins using equation (2). Measured mass and mass fractions $w_{i}$ are listed in Table 2

\begin{tabular}{lccc}
\hline Sample & Material & $\mathrm{m}[\mathrm{mg}]$ & $w_{i}[\%]$ \\
\hline Kurush & $\mathrm{Au}$ & $1052.64 \pm 12.54$ & $58.44 \pm 0.70$ \\
\hline Pfennig & $\mathrm{Ag}$ & $17.97 \pm 0.16$ & $5.62 \pm 0.05$ \\
$(1745)$ & $\mathrm{Cu}$ & $265.72 \pm 5.49$ & $83.17 \pm 1.72$ \\
\hline Kreutzer & $\mathrm{Cu}$ & $3682.40 \pm 96.71$ & $94.95 \pm 2.49$ \\
$(1843)$ & & & \\
\hline Parvus & $\mathrm{Ag}$ & $49.11 \pm 0.43$ & $13.67 \pm 0.12$ \\
& $\mathrm{Cu}$ & $194.81 \pm 4.65$ & $54.22 \pm 1.29$ \\
\hline Centessimo & $\mathrm{Cu}$ & $1312.61 \pm 11.46$ & $99.95 \pm 0.87$ \\
& $\mathrm{In}$ & $(12.34 \pm 0.58) \cdot 10^{-3}$ & $(76.10 \pm 4.42) \cdot 10^{-5}$ \\
\hline Heller & $\mathrm{Ag}$ & $2.01 \pm 0.31$ & $0.04 \pm 0.01$ \\
& $\mathrm{Cu}$ & $4797.12 \pm 77.15$ & $93.83 \pm 1.51$ \\
\hline Pfennig & $\mathrm{Ag}$ & $37.48 \pm 0.99$ & $12.82 \pm 0.34$ \\
$(1776)$ & $\mathrm{Cu}$ & $265.88 \pm 6.71$ & $90.96 \pm 2.29$ \\
\hline Korona & $\mathrm{Ag}$ & $2674.09 \pm 3.097$ & $54.98 \pm 0.64$ \\
& $\mathrm{Cu}$ & $448.64 \pm 11.9$ & $9.22 \pm 0.42$ \\
\hline Kreutzer & $\mathrm{Cu}$ & $2889.20 \pm 71.95$ & $92.89 \pm 2.31$ \\
$(1861)$ & & & \\
\hline
\end{tabular}

TABLE 2. Determined composition of irradiated coins [3].

Parameters of radioactive decays from 4, such as the half-life period, energy and intensity of gamma radiation, were used to assign the observed gamma lines in measured spectra to specific radionuclides. Then according to the neutron energies reached in thermal nuclear reactors, cross-sections, and natural isotopic composition, the observed radionuclides were assigned to considered materials. Qualitative analysis of composition was carried out in this way for the coin Heller. Except the contribution of natural background, the gamma spectrum of Heller (see Fig. 5) contains the gamma lines of ${ }^{64} \mathrm{Cu},{ }^{110 \mathrm{~m}} \mathrm{Ag}$ marked in blue color, and then ${ }^{122} \mathrm{Sb},{ }^{124} \mathrm{Sb},{ }^{76} \mathrm{As}$ and ${ }^{24} \mathrm{Na}$ as well. Observed radionuclides referred to presence of antimony, arsenic, mercury, silver and sodium in irradiated samples.

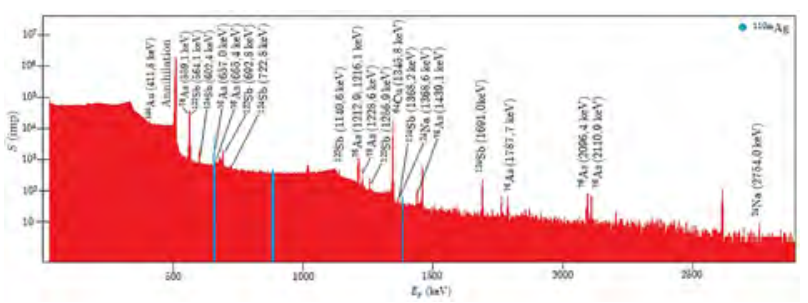

FigURE 5. Analyzed gamma spectrum of Heller. 


\subsection{NeUtron SPECTRUM RECONSTRUCTION}

Reaction rates of interaction observed in used activation detectors through produced radionuclides covered all the energy regions of neutron spectra for typical thermal reactor. The use of cadmium cover enabled to separate the contributions of thermal and epithermal neutrons. Threshold interactions served to determine the response of detector to the fast neutron. Using nuclear data from ENDF/B-VII.1 [5], the neutron spectrum was determined according to equation (4). The irradiation position in the fuel cell dummy with the overmoderated neutron spectrum allowed to utilize the Westcott formalism. Separately described energy regions of neutron spectrum together with the discrete points of neutron flux, associated with the most significant resonances in activation cross-sections, and total neutron flux, determined using analytical methods, are depicted in Fig. 6] and Fig. 7 respecitvely.

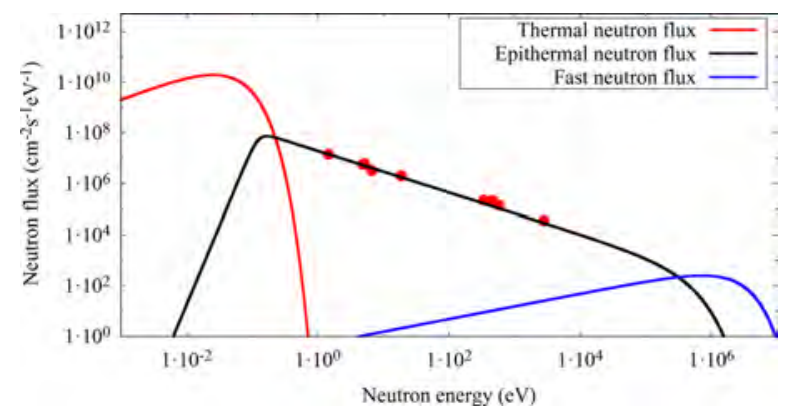

Figure 6. Analytic description of neutron flux regions.

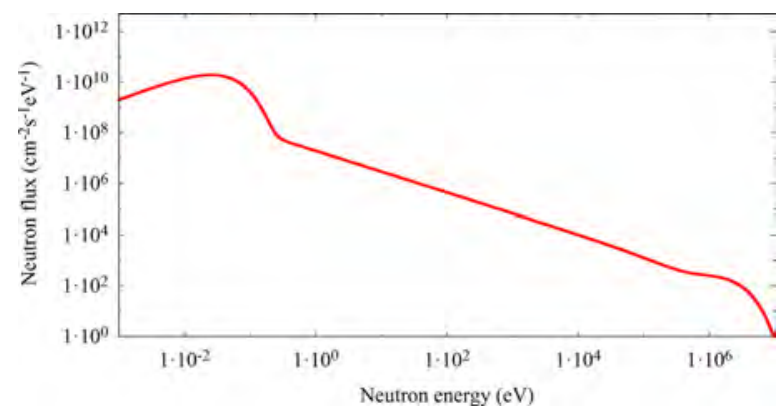

FigURE 7 . Total neutron flux determined by analytical methods.

Results obtained by analytical methods were compared to numerical solution using the unfolding procedure of SAND-II code 6. As the input (guess) neutron spectrum requested for the deconvolution process, the analytical spectrum was used. In the 5 th iteration and using nuclear data from the ENDF/BVII.1 data library and experimentally determined reaction rates, the neutron spectrum in 36 energy bins from $10^{-12} \mathrm{MeV}$ to $10^{1} \mathrm{MeV}$ was successfully unfolded. Comparison of determined numerical and analytical neutron spectrum in the mid-height of reactor core of VR-1 training reactor is in Fig. 8. Calculated ratios $C / E$, representing calculated over experimental reaction rates rations, as a parameter of spectrum unfolding, are listed in Table 3 .

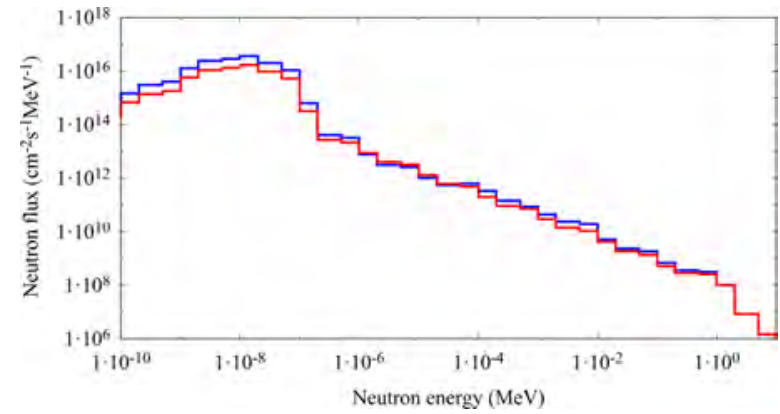

Figure 8. Comparison of analytical and unfolded spectrum.

\begin{tabular}{cccc}
\hline Reaction & $C / E[-]$ & Reaction & $C / E[-]$ \\
\hline${ }^{197} \mathrm{Au}(\mathrm{n}, \gamma){ }^{198} \mathrm{Au}$ & 0.92 & ${ }^{56} \mathrm{Fe}(\mathrm{n}, \mathrm{p}){ }^{56} \mathrm{Mn}$ & 0.99 \\
${ }^{63} \mathrm{Cu}(\mathrm{n}, \gamma){ }^{64} \mathrm{Cu}$ & 0.87 & ${ }^{55} \mathrm{Mn}(\mathrm{n}, \gamma){ }^{56} \mathrm{Mn}$ & 0.84 \\
${ }^{115} \mathrm{In}(\mathrm{n}, \gamma){ }^{116 \mathrm{~m}} \mathrm{In}$ & 1.18 & ${ }^{176} \mathrm{Lu}(\mathrm{n}, \gamma){ }^{177} \mathrm{Lu}$ & 1.06 \\
$\left.{ }^{23} \mathrm{Na}(\mathrm{n}, \gamma)\right)^{24} \mathrm{Na}$ & 1.03 & ${ }^{37} \mathrm{Cl}(\mathrm{n}, \gamma){ }^{38} \mathrm{Cl}$ & 0.92 \\
${ }^{27} \mathrm{Al}(\mathrm{n}, \alpha){ }^{24} \mathrm{Na}$ & 1.06 & ${ }^{238} \mathrm{U}(\mathrm{n}, \gamma){ }^{239} \mathrm{U}$ & 1.01 \\
\hline
\end{tabular}

TABLE 3. $C / E$ ratios of reactions used for the spectrum unfolding.

\section{Conclusions}

According to the experiences and results of activation experiments, the VR-1 reactor is suitable for analyzing of composition of historical samples, especially coins. Table 2 clearly shows the possibilities of determination of all materials commonly used in coin production, such as gold, silver, or copper. Main advantages of VR-1 training reactor is the possibility of easy way of inserting samples into irradiating position in vertical channel and relatively low reactor power, comparing to others research reactors in Czech Republic, so it is hard to produce emitters of very high activities.

The first time used method of analytical spectrum description in full energy range showed the new possibility of neutron spectrum determination using the activation detectors at VR-1 reactor. Moreover, the analytical spectrum corresponds to expectations, but compared to results of numerical solution using the SAND-II unfolding code appears slightly undervalued in the thermal energy region. This brings a new way of potential further specifying of the analytical spectrum description.

Results illustrated in this paper are a summary of outcome achieved within the Bachelor's thesis in 20132014 and the Master's degree project in 2015-2016.

\section{REFERENCES}

[1] C. Westcott, W. Walker, T. Alexander. Effective cross sections and cadmium ratios for the neutron spectra of thermal reactors. Tech. rep., Atomic Energy of Canada Ltd., 1959. Conference: 2. United Nations International Conference on the Peaceful Uses of Atomic Energy, Geneva (Switzerland), 1958. http://www.osti.gov/scitech/biblio/4279663

[2] H.-L. Pai, P.-Y. Ma, S.-C. Wang, W. S. Lee. Measurement of epithermal neutron spectra by 
resonance detectors. Nuclear Science and Engineering 9(4):519-520, 1961.

[3] J. Šturma. Neutronová aktivačni analýza historických předmětu na školním reaktoru VR-1. Bachelor's thesis, KJR FJFI, České vysoké učení technické v Praze, 2014.

[4] S. Chu, L. Ekström, R. Firestone. The Lund/LBNL nuclear data search, version 2.0, February 1999. http://nucleardata.nuclear.lu.se/toi/.
[5] National Nucelar Data Center. ENDF/B-VII.1 evaluated nucelar data library. http://www.nndc.bnl.gov/endf/b7.1/

[6] P. Griffin, J. Kelly, J. VanDenburg. User's manual for SNL-SAND-II code. Tech. Rep. SAND93-3957, Sandia National Laboratories, 1994. http://prod.sandia. gov/techlib/access-control.cgi/1993/933957.pdf 